\title{
The antifungal activity of aqueous and alcoholic extract of mushroom (Agaricus bisporus) against Aspergillus flavus
}

\author{
${ }^{1}$ Safa M. Sultan, ${ }^{1}$ Janan K. AL-Tarjuman and ${ }^{2}$ Maha El Aldory \\ ${ }^{1}$ Northern Technical University, ${ }^{2}$ Ministry of Education Mosul, IRAQ
}

\begin{abstract}
Antifungal activity of aqueous and ethanol extracts of Agaricus bisporus were computed in vitro against Aspergillus flavus following poison food technique using different concentration $(5,10,15,20,25,30 \mathrm{mg} / \mathrm{ml})$ for aqueous extract and $(2,4,6,8,10$, $16 \mathrm{mg} / \mathrm{ml}$ ) for ethanol extract. the maximum effect of ethanolic extract against Aspergillus flavus growth was achieved at concentration $10 \mathrm{mg} / \mathrm{ml}$, the growth rate reach $1.25 \mathrm{~cm}$ while the maximum effect of ethanolic extract achieved at concentration $16 \mathrm{mg} / \mathrm{ml}$, the growth rate reaches $2.5 \mathrm{~cm}$.
\end{abstract}

Keywords: mushroom, antifungal activity, antifugal, A.flavus

\section{Introduction}

Agaricus bisporus, is an edible basidiomycete fungus and the most widely cultivated mushrooms in the world, best known as table mushroom. the most familiar form bears white cap, brown gills as well as stalk and flesh (Jagadish et al., 2009).

Plants, mushrooms and other natural sources represent the origin of biologically active compounds, Mushrooms to live in their usual surroundings need antibacterial and antifungal compounds, therefore many mushroom species can act as good source for antifungal compounds which could be beneficial for humans (Yamaç and Bilgili, 2006). Pathogenic fungi result in great loss in humans, crops, farm animals, and other organisms. Moreover, fungal invasion in agriculture leads to a severe reduction in the yield quality of crops and bears massive economic losses. Introducing genes into crops encoding antifungal proteins to encourage their resistance against fungal pathogens may supply ways to treat the problem, (Chu et al, 2005 and Wong et al, 2010). There are two main reasons behind the raises of global interests from the scientific and clinical community to use of mushrooms with potential therapeutic properties First, mushrooms proved their efficiency against many diseases and serious metabolic disorders such as cancer. Secondly, there are many origin sources for fungal bioactive metabolites (wild, mycelial biomass, cultivated fruiting bodies and supernatant of submerged cultured) (Poucheret et al, 2006). The present work detailed and evaluate the effect of aqueous and alcoholic extract of edible mushroom (Agaricus biosporus) against pathogenic fungus Aspergillus flavus, the random use of drugs by means of commercial antimicrobial it results in drug resistance into human pathogenic microorganisms which encourage the scientists to search new substance act as active antimicrobial from different sources (Karaman et al, 2003).

\section{Material and methods}




\subsection{Tested organisms:}

A. The mushroom (Agaricus bisporus) used in this study was obtained from local markets in Mosul, Nineveh province, Iraq

B. Aspergillus flavus strain isolated from fruits and identified according to the color and general morphology using light microscope (Pitt and Hocking, 2009).

\subsection{Identification of Aspergillus flavus}

Aspergillus flavus was identified to specie level by inoculating on Malt Extract Agar (MEA), Czapek Yeast Extract Agar (CYA), and $25 \%$ Glycerol Nitrate Agar (G25\%N) at 25 and $37^{\circ} \mathrm{C}$ for 7 days, and identified by using the identification keys from (Pitt and Hocking, 2009).

\subsection{Preparation of Agaricus bisporus crude extracts}

To prepare the mushroom aqueous extract fresh fruiting body was washed twice and rinsed with distilled water, and dried in shade condition, and grounded into powder by a grinder, $5 \mathrm{gm}$ of powder was soaked in $50 \mathrm{ml}$ of water and ethanol (96\%) and incubated for $36 \mathrm{hr}$ at room temperature. Whatman filter no 4 was used to filtrate the extracts, water bath at $100^{\circ} \mathrm{C}$ for water and at $78^{\circ} \mathrm{C}$ for ethanol used to evaporate the extra solvent from the filtrate, the differences in weights before and after evaporation were calculated (Ejikeme and Henrietta, 2010) and (Jain and Choudhary, 2012). The extracts stored at $4{ }^{\circ} \mathrm{C}$ in a sterile container for further use.

\subsection{Screening the antifungal activity of Agaricus bisporus:}

Screening the antifungal activity of mushroom (Agaricus bisporus) was done according to poison food technique (Alves et al, 2012) $3 \mathrm{ml}$ of each extract incorporated in the culture medium Potato Dextrose Agar (PDA) at concentration $(5,10,15,20,25.30 \mathrm{mg} / \mathrm{ml})$ for aqueous extract and $(2,4,6,8,10,16 \mathrm{mg} / \mathrm{ml})$ for alcoholic extract.

To determine the antifungal activity of aqueous and alcoholic extracts of Agaricus bisporus the colony growth rate in the poisoned plate and non-poisoned plate(control) was compared, the colony growth rate was measured by considering the two orthogonal mean diameters of the colony.

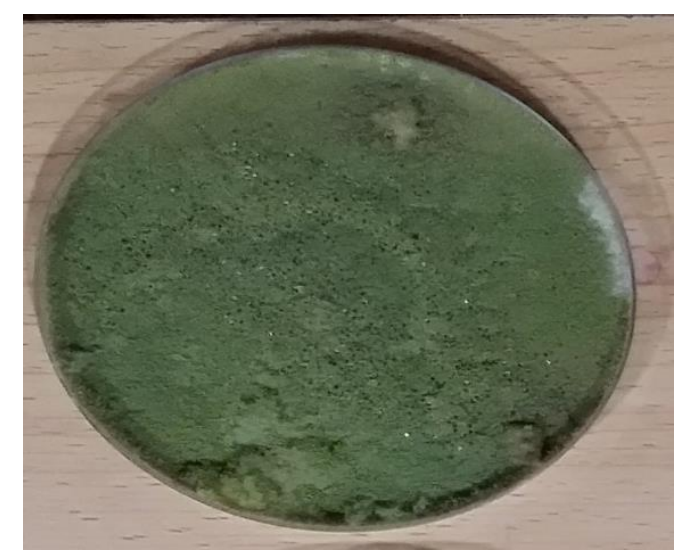

Fig. 1: Aspergillus flavus isolate on Potato Dextrose Agar Media

\section{Result and Discussion}

\subsection{Aspergillus flavus identification:}


Aspergillus flavus was identified according to agricultural and microscopic features and ensured by inoculating on Malt Extract Agar (MEA), Czapek Yeast Extract Agar (CYA), and $25 \%$ Glycerol Nitrate Agar $(\mathrm{G} 25 \% \mathrm{~N})$ at 25 and $37^{\circ} \mathrm{C}$ for 7 days, and identified by using the identification keys from (Pitt and Hocking, 2009).

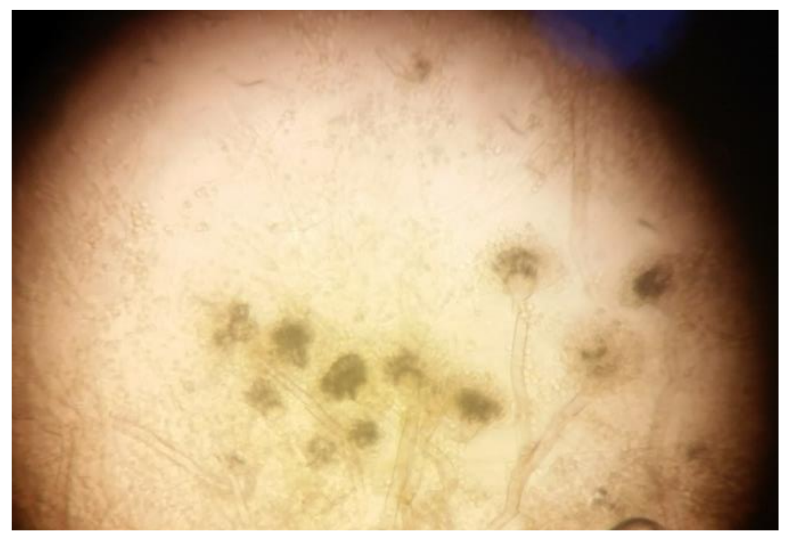

Fig. 2: Aspergillus flavus isolate under a microscope (40x)

\subsection{Antifungal activity:}

The results of the antifungal response shown by the aqueous and alcoholic extract of Agaricus bisporus are summarized in tables (1\&2) and figures 3,4 and 5.

Table (1): The effect of aqueous extract of Agaricus bisporus on the growth of Aspergillus flavus

\begin{tabular}{|c|c|c|}
\hline Sr.no & $\begin{array}{c}\text { The } \\
\text { concentration } \\
\text { of aqueous } \\
\text { extract }(\%)\end{array}$ & $\begin{array}{c}\text { Colony } \\
\text { growth rate } \\
\text { (cm) }\end{array}$ \\
\hline 1 & Cont. & 8.5 \\
\hline 2 & 5 & 2.75 \\
\hline 3 & 10 & 1.25 \\
\hline 4 & 15 & 2.5 \\
\hline 5 & 20 & 2.25 \\
\hline 6 & 25 & 2.25 \\
\hline 7 & 30 & 2.5 \\
\hline
\end{tabular}




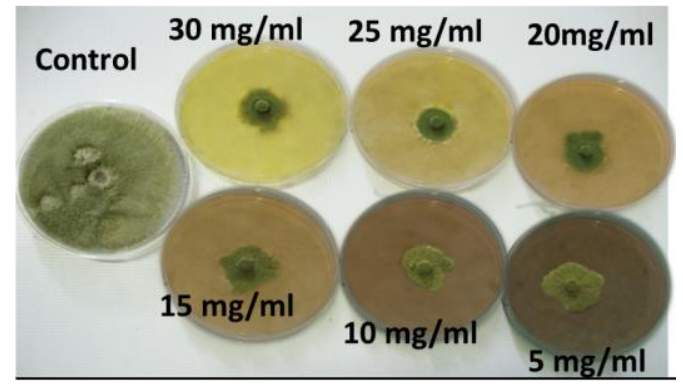

Fig. 3: The effect of aqueous extract of Agaricus bisporus on the growth of Aspergillus flavus

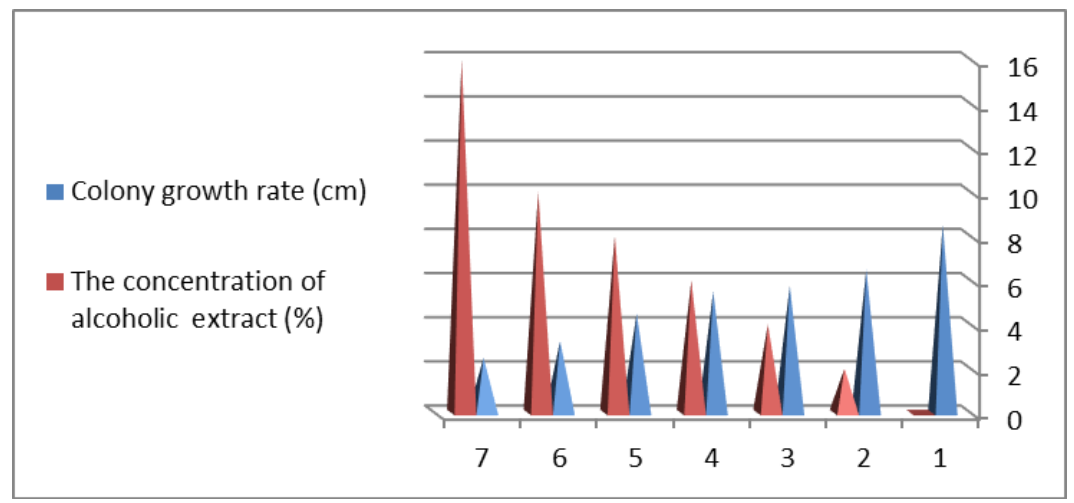

Fig. 4: The effect of aqueous extract of Agaricus bisporus on the growth of Aspergillus flavus

Table (2): The effect of alcoholic extract of Agaricus bisporus on the growth of Aspergillus flavus

\begin{tabular}{|c|c|c|}
\hline Sr.no & $\begin{array}{c}\text { The } \\
\text { concentration of } \\
\text { alcoholic } \\
\text { extract (\%) }\end{array}$ & $\begin{array}{c}\text { Colony } \\
\text { growth rate } \\
\text { (cm) }\end{array}$ \\
\hline 1 & Cont. & 8.5 \\
\hline 2 & 2 & 6.5 \\
\hline 3 & 4 & 5.75 \\
\hline 4 & 6 & 5.5 \\
\hline 5 & 8 & 4.5 \\
\hline 6 & 10 & 3.25 \\
\hline 7 & 16 & 2.5 \\
\hline
\end{tabular}




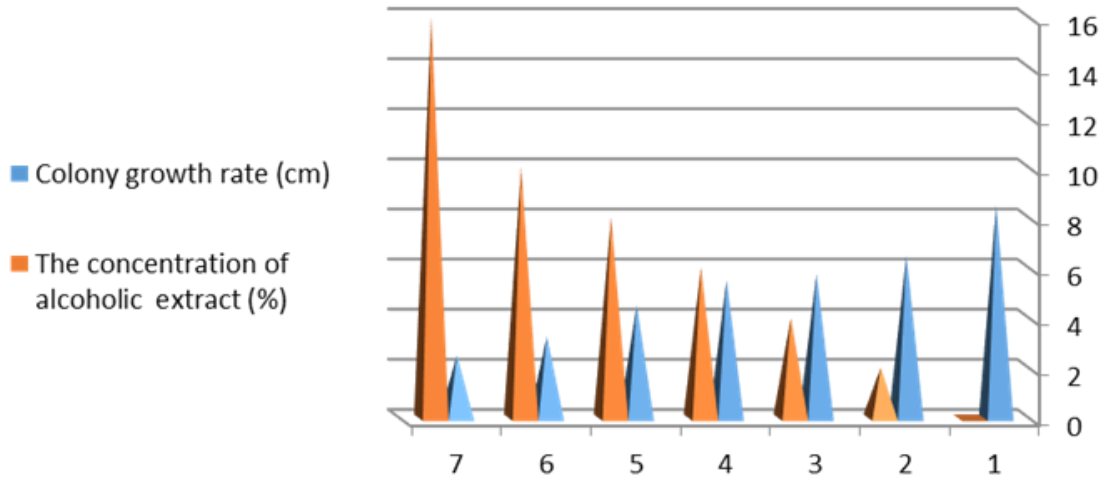

Fig (5) : The effect of alcoholic extract of Agaricus bisporus on the growth of Aspergillus flavus

There was an obvious activity of aqueous and alcoholic extract on the growth of A.flavus, the maximum effect of aqueous extract was achieved at concentration $10 \mathrm{mg} / \mathrm{ml}$, the growth rate reached $1.25 \mathrm{~cm}$ while the maximum effect of alcoholic extract archived at concentration $16 \mathrm{mg} / \mathrm{ml}$, the growth rate reach $2.5 \mathrm{~cm}$. Mushrooms are rich with proteins and compounds which show antifungal, antibacterial and anti-viral activities, polypeptide alveolarin and peptide eryngin have extremely antifungal activity (Turkoglu et. Al., 2006, Wang and Ng, 2000, Wang et.al., 2004, Solak et.al., 2006, Cohen et.al., 2002, Bender et.al., 2001). There are many studies refried to the antimicrobial activity of mushroom extracts against many microorganisms (Barros et.al., 2007 and Demirhan et.al., 2007). Kumar and Yadav, 2014 report that the ethanolic extract of Agaricus bisporus exhibited antifungal activity against A.flavus. Öztürk et al. 2011 reported antifungal activity of methanolic extracts of A. bisporus, A. essettei and A. bitorquis against Candida albicans while Barros et al. 2008 could not found the activity of Agaricus bisporus against Candida albicans.

\section{Conclusion:}

It was concluded from the results of the present work, the aqueous and ethanol extract of Agaricus bisporus showed good activity against A.flavus, so that Agaricus bisporus is useful for health and could be used as a natural source of the antifungal agent in enlargement new drug for fungal infections instead of the use of commercial antifungal drugs which result in drug resistance.

\section{References:}

1. Alves, M.J.; Ferreira, I.C.F.R.; Dias, J.; Teixeira, V.; Martins, A. and Pintado, M.A. (2012). Review on antimicrobial activity of mushroom (Basidiomycetes) extracts and isolated compounds. Planta Med. 78: 1707-1718.

2. Barros, L.; Calhella, R.C. and Vaz, J.A. (2007). Antimicrobial activity and bioactive compounds of Portugese wild edible mushrooms methanolic extracts. European Food 
Research and Technology. 225: 151- 156.

3. Barros, L.; Cruz, T.; Baptista, P.; Estevinho, L.M.; Ferreira, I.C.F.R. (2008). Wild and commercial mushrooms as source of nutrients and nutraceuticals. Food Chem. Toxicol.46, 2742-2747.

4. Bender, S.; Lonergan, G.T.; Backhaus, J. Dumitrache, A. and Baker, W.L. (2001). The antibacterial activity of the edible and medicinal mushroom Lentinus edodes (Berk.) Sing. Int. J. Med. Mushrooms 3: 118.

5. Chu, K.T.; Xia, L. and Ng, T.B. (2005). Pleurostrin, an antifungal peptide from the oyster mushroom. Peptides. 26: 2098-2103.

6. Cohen, R.; Persky, L. and Hadar, Y. (2002). Biotechnological applications and potential of wood-degrading mushrooms of the genus Pleurotus. Appl. Microbiol. Biotechnol. 58: 582594.

7. Demirhan, A.; Yesil, O.F.; Yildiz, A. and Gul, K. (2007). A research on antimicrobial activity of some macrofungi species. Science and Engineering Journal of Firat University. 19: 425433.

8. Ejikeme, N. and Henrietta O. U. (2010) Antimicrobial activity of some local mushrooms on pathogenic isolates. J. Med. Plant Res. 4 (23): 2460-2465.

9. Jagadish, L.K.; Venkata Krishnan, V.; Shenbhagaraman, R. and Kaviyarasan, V. (2009). Comparative study on the antioxidant, anticancer and antimicrobial property of Agaricus bisporus (J. E.Lange) Imbach before and after boiling. Afr. J. Biotechnol., 8(4): 654661.

10. Jain, P. and Choudhary, S. (2012). Evaluation of antimicrobial and antioxidant activities and phytochemical analysis of white button mushroom Agaricus bisporus. Int. J. Pharm. Sci. Rev. Res. 15(2): 85-89.

11. Karaman, Y.; Bin, S.A.; Gu, F.; lluce, M.; Gutcuo Sengu, H.1.M., Ad gu, Z.A. (2003). Antimicrobial activity of aqueous and methanol extracts of Juniperus oxycedrus L. J. Ethnopharmacol., 85: 213235.

12. Kumar, V. and Yadav, U. (2014). Screening of antifungal activity of Pleurotus ostreatus and Agaricus bisporus . Biolife.2(3): 918-923.

13. Öztürk, M.; Duru, M.E.; Kivrak, S.; Mercan-Doğan, N.; Türkoglu, A.; Özler, M.A. (2011). In vitro antioxidant, anticholinesterase and antimicrobial activity studies on three Agaricus species with fatty acid compositions and iron contents: A comparative study on the three most edible mushrooms. Food Chem. Toxicol. 49, 1353-1360.

14. Pitt, J.I. and Hocking, A.D. (2009). Fungi and Food Spoilage, $3^{\text {nd }}$ ed. Springer., 519 pp.

15. Poucheret, P.; Fons, F. and Rapior, S. (2006). Biological and pharmacological activity of higher fungi: 20-Year retrospective analysis. Mycologie 27(4):311-333.

16. Solak, M.H.; Kalmis, E.; Saglam, H. and Kalyoncu, F. (2006). Antimicrobial activity of two wild mushrooms Clitocybe alexandri (Gill.) Konr. and Rhizopogon roseolus (Corda) T.M. Fries collected from Turkey. Phytotherapy Research. 20: 1085-1087.

17. Turkoglu, A.; Kivrak, I.; Mercan, N.; Duru, M.E.; Gezer, K. and Turkoglu, H. (2006). Antioxidant and antimicrobial activities of Morchella conica. Pers. African Journal of Biotechnol. 5: 1146-1150.

18. Wang, H.X. and Ng, T.B. (2000). Isolation of a novel ubiquitin-like protein from Pleurotus ostreatus mushroom with anti-human immunodeficiency virus, translation- inhibitory and ribonuclease activities. Biochem. Biophys. Res. Commun. 276: 587-93.

19. Wong, J.H.; Ng, T.B.; Cheung, R.C.F.; Ye, X.J.; Wang, H.X.; Lam, S.K.; Lin, P.; Chan, Y.S.; Fang, E.F.; Ngai, P.H.K.; Lia, L.X.; Ye, X.Y.; Jiang, Y. and Liu, F. (2010). Proteins with antifungal properties and other medicinal applications from plants and mushrooms. Appl. 
Microbiol. Biotechnol.87, 1221-1235.

20. Wang, H.X.; Ng, T.B. and Liu, Q.H. (2004). Alveolarin, a novel antifungal polypeptide from the wild mushroom Polyporus alveolaris. Peptides 25: 693-696.

21. Yamaç, M. and Bilgili, F. (2006). Antimicrobial activities of fruit bodies and/or mycelial cultures of some mushroom isolates. Pharm. Biol. 4(9): 660-667. 